\title{
Conifer Health Classification for Colorado, 2008
}

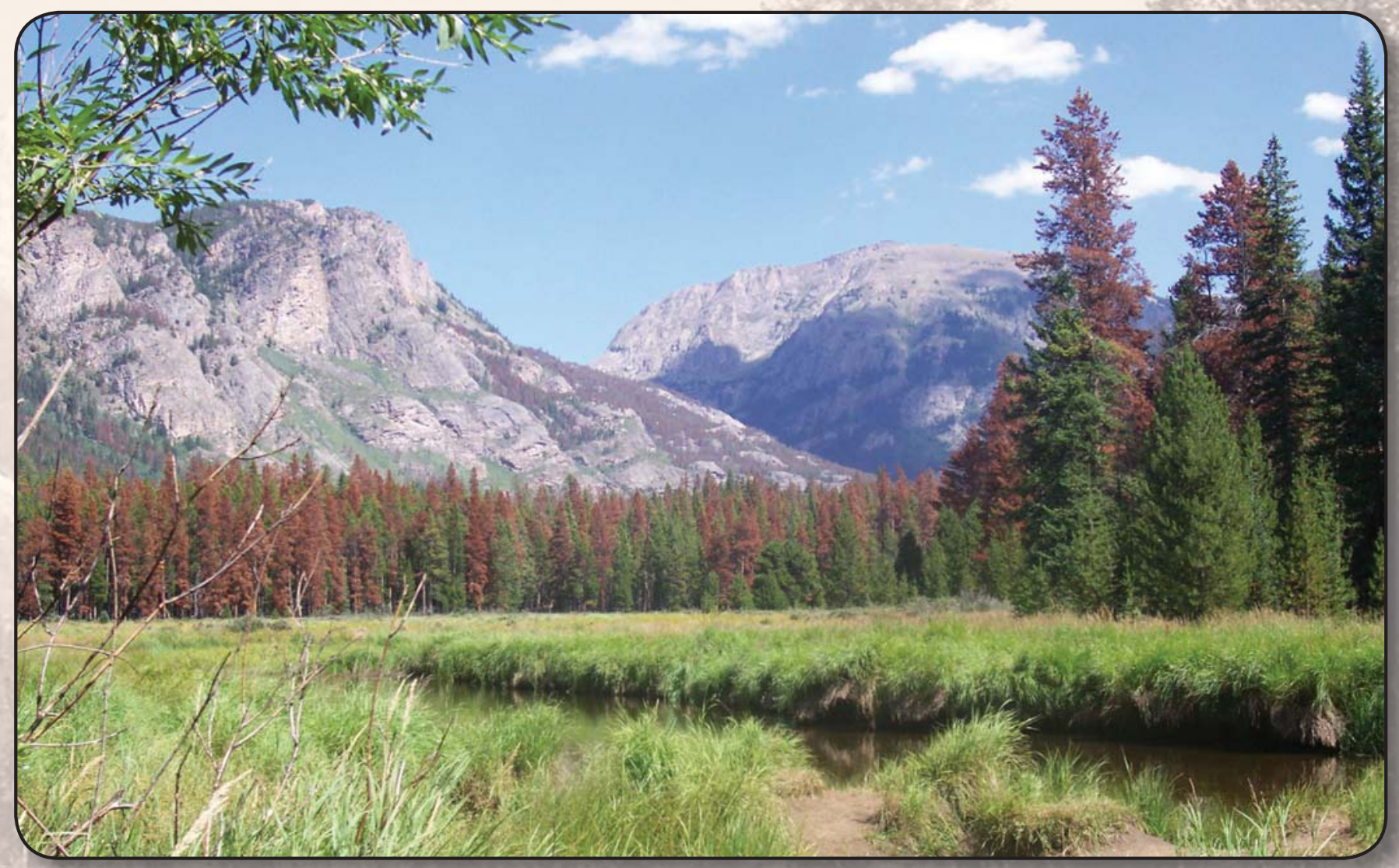

Pamphlet to accompany

Scientific Investigations Map 3103 


\section{FRONT COVER:}

Conifer forest in Colorado, near Grand Lake.

Photograph by C.J. Cole, 2007. 


\section{Conifer Health Classification for Colorado, 2008}

By Christopher J. Cole, Suzanne M. Noble, Steven L. Blauer, Beverly A. Friesen, Stacy E. Curry, and Mark A. Bauer

Pamphlet to accompany

Scientific Investigations Map 3103 


\title{
U.S. Department of the Interior \\ KEN SALAZAR, Secretary \\ U.S. Geological Survey \\ Marcia K. McNutt, Director
}

\section{U.S. Geological Survey, Reston, Virginia: 2010}

\author{
For more information on the USGS — the Federal source for science about the Earth, its natural and living resources, \\ natural hazards, and the environment, visit http://www.usgs.gov or call 1-888-ASK-USGS \\ For an overview of USGS information products, including maps, imagery, and publications, \\ visit http://www.usgs.gov/pubprod \\ To order this and other USGS information products, visit http://store.usgs.gov
}

\begin{abstract}
Any use of trade, product, or firm names is for descriptive purposes only and does not imply endorsement by the U.S. Government.

Although this report is in the public domain, permission must be secured from the individual copyright owners to reproduce any copyrighted materials contained within this report.
\end{abstract}

Suggested citation:

Cole, C.J., Noble, S.M., Blauer, S.L., Friesen, B.A., Curry, S.E., and Bauer, M.A., 2010, Conifer health classification for Colorado, 2008: U.S. Geological Survey Scientific Investigations Map 3103, 11 p. pamphlet, 1 sheet, scale 1:650,000. (Available at URL http://pubs.usgs.gov/sim/3103). 


\section{Contents}

Abstract
Introduction
Study Area
$\quad$ Sage Processing
Landing
Results and Verification
Summary
Acknowledgments
References Cited

\section{Figures}

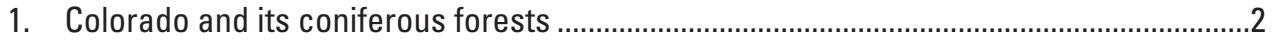

2. Colorado Landsat 5 Thematic Mapper coverage ……..................................................

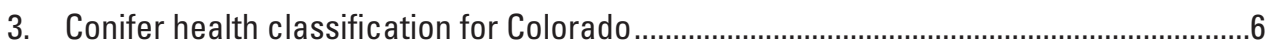

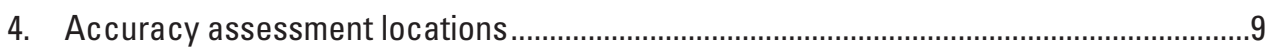

\section{Tables}

1. Scenes used to derive the conifer classification ............................................................

2. Accuracy assessment results for the conifer classification.............................................

\section{Conversion Factors}

Inch/Pound to SI

\begin{tabular}{lcl}
\hline Multiply & By & To obtain \\
\hline meter $(\mathrm{m})$ & Length & \\
kilometer $(\mathrm{km})$ & 3.281 & foot $(\mathrm{ft})$ \\
& 0.6214 & mile $(\mathrm{mi})$ \\
\hline square meter $\left(\mathrm{m}^{2}\right)$ & Area & \\
square kilometer $\left(\mathrm{km}^{2}\right)$ & 10.76 & square foot $\left(\mathrm{ft}^{2}\right)$ \\
& .3861 & square mile $\left(\mathrm{mi}^{2}\right)$ \\
\hline
\end{tabular}

Vertical coordinate information is referenced to the North American Vertical Datum of 1988 (NAVD 88).

Horizontal coordinate information is referenced to the North American Datum of 1983 (NAD 83).

Altitude, as used in this report, refers to distance above the vertical datum. 



\title{
Conifer Health Classification for Colorado, 2008
}

\author{
By Christopher J. Cole, ${ }^{1}$ Suzanne M. Noble, ${ }^{1}$ Steven L. Blauer, ${ }^{2}$ Beverly A. Friesen, ${ }^{2}$ Stacy E. Curry, ${ }^{2}$ \\ and Mark A. Bauer ${ }^{1}$
}

\section{Abstract}

There is a lack of appropriate geospatial data regarding conifer forest health within Colorado at the landscape level. Colorado has undergone substantial changes in forests due to urbanization, wildfires, insect-caused tree mortality, and other human and environmental factors. The U.S. Geological Survey Rocky Mountain Geographic Science Center evaluated and developed a methodology for applying remotelysensed imagery for assessing conifer health in Colorado. Two classes were identified for the purposes of this study: healthy and unhealthy (for example, an area the size of a 30- $\times 30$-m pixel with 20 percent or greater visibly dead trees was defined as "unhealthy").

Medium-resolution Landsat 5 Thematic Mapper imagery were collected statewide, and converted to at-sensor reflectance to reduce inter-scene variability due to differences in solar elevation and acquisition date. Cloud cover-affected Landsat pixels were identified and replaced with the most recent, best available cloud-free data, and were normalized via linear regression based upon pseudo-invariant features (PIFS), whose spectral values should not appreciably change by scene date. The normalized, reflectance-converted, cloud-filled Landsat scenes were merged to form a statewide image mosaic, and a Normalized Difference Vegetation Index (NDVI) and Renormalized Difference Infrared Index (RDII) were derived. The National Landcover Database for 2001 was updated to account for current conifer cover within Colorado.

A supervised maximum likelihood classification was done using the Landsat multispectral bands, the NDVI, the RDII, and 30-m U.S. Geological Survey National Elevation Dataset (NED). The classification was constrained to pixels identified in the updated landcover dataset as coniferous or mixed coniferous/deciduous vegetation. The statewide results were merged with a separate health assessment of Grand County, Colo., produced in late 2008. This assessment was done using similar sampling and classification schema and methodologies as the statewide effort. Without the inclusion

${ }^{1}$ Parallel Inc., P.O. Box 281149, Lakewood, CO 80228

${ }^{2}$ USGS Rocky Mountain Geographic Science Center, P.O. Box 25046, MS 516, Denver, CO 80225 of this classification, a significantly larger portion of the State assessment would have been derived using pre-2008 imagery due to persistent cloud cover affecting this area of interest. USGS work within Grand County has confirmed significant vegetation mortality which would not have been captured using earlier data.

Sampling and validation was done by collecting field data and high-resolution imagery. The 86 percent overall classification accuracy attained in this study suggests that the data and methods used successfully characterized conifer conditions within Colorado. Although forest conditions for Lodgepole Pine (Pinus contorta) are easily characterized, classification uncertainty exists between healthy/unhealthy Ponderosa Pine (Pinus ponderosa), Piñon (Pinus edulis), and Juniper (Juniperus sp.) vegetation. Some underestimation of conifer mortality in Summit County is likely, where recent (2008) cloud-free imagery was unavailable. These classification uncertainties are primarily due to the spatial and temporal resolution of Landsat, and of the NLCD derived from this sensor. It is believed that high- to moderate-resolution multispectral imagery, coupled with field data, could significantly reduce the uncertainty rates. The U.S. Geological Survey produced a four-county follow-up conifer health assessment using high-resolution RapidEye remotely sensed imagery and field data collected in 2009.

\section{Introduction}

Currently, there is a lack of appropriate geospatial data regarding conifer forest health within Colorado at the landscape level. Colorado has undergone significant changes in both forest spatial extent and health in recent years due to natural and anthropogenic causes. These changes are not adequately characterized by existing landcover/vegetation datasets at a suitable spatial scale, nor with the timeliness requested by Federal, State, and local planners within the forest and fire communities who need this strategic information. Multi-year aerial surveys exist covering much of Colorado and are a useful product for determining general forest conditions. These surveys have limitations including spatial accuracy and do not employ remotely sensed data sensitive to the near infrared spectrum, which has been widely used in vegetation health studies (Elvidge and Chen, 1995; Vogelmann and Rock, 
1988; Vogelmann, 2002). U.S. Geological Survey (USGS)

Landscape Fire and Resource Management Planning Tools Project (LANDFIRE, http://www.landfire.gov/) information, while invaluable, cannot fully capture existing forest conditions due to the date of remotely sensed imagery utilized to derive it (circa 2000).

The U.S. Geological Survey (USGS) Rocky Mountain Geographic Science Center (RMGSC) evaluated the feasibility of developing a methodology using medium-resolution remotely sensed imagery for the assessment of conifer health throughout Colorado. A decision tree rules-based classification approach was tested in an earlier pilot study spanning Grand County. This study had slightly lower classification results than the maximum likelihood algorithm used for that assessment. As such, this approach was not used for the subsequent statewide mapping effort. This report adapts techniques and results produced by the pilot study which characterized conifer conditions within Grand County, Colo. (unpub. data, Christopher J. Cole, Parallel, Inc., 2008). The USGS applied these methodologies to provide a scientifically rigorous and repeatable landscape-level assessment of coniferous forest health statewide through the use of medium-resolution Landsat 5 Thematic Mapper imagery and derivatives. A modified National Landcover Database (NLCD), specifically updated by the RMGSC to account for current forest cover in Colorado, was also used. Sampling and validation were accomplished by collecting field data and Quickbird imagery (DigitalGlobe, http://digitalglobe.com).

This study does not attempt to characterize the historical range of ecological conditions within Colorado's conifer forests, nor does it distinguish existing from desired conifers in relation to spatial range and density. As such, this study should be differentiated from historical range in variability (HRV) work (Nonaka and Spies, 2005; Veblen and Donnegan, 2005). The RMGSC has sought to quantify the physical health of existing conifer vegetation cover at landscape scale as estimated by medium-resolution remotely-sensed imagery correlated with field information and high-resolution data.

\section{Study Area}

Colorado (fig. 1) was selected as the study area for this analysis. The 8th largest state in the United States, Colorado spans $104,000 \mathrm{mi}^{2}\left(269,600 \mathrm{~km}^{2}\right)$, and contains a diverse range of land-cover, land ownership, and coniferous forest health conditions. Colorado has 22 million acres of forested lands, a significant portion of which are coniferous. The State has undergone substantial changes in forests due to urbanization, wildfires, insect-caused tree mortality, and other human and environmental factors. Colorado is host to ongoing USGS fire-science activities (http://fire-research.cr.usgs.gov/) which seek to utilize remote sensing and other geospatial information to investigate the relationship between landscape level conifer mortality and elevated wildfire risk.

\section{Image Processing}

Landsat Thematic Mapper was used for this study because the sensor offers spatial resolution discrete enough to characterize health conditions at forest landscape level. Landsat archival coverage is available spanning the entire study area (fig. 2). The USGS recently made the collection available free of charge at http://glovis.usgs.gov/.

Over fifty orthorectified Landsat 5 Thematic Mapper scenes were obtained by the RMGSC from the USGS Earth Resources Observation and Science Center (EROS, http://eros.usgs.gov/). The majority of these scenes were from the USGS Global Visualization Viewer Landsat archive (GloVis, http://glovis.usgs.gov/). The image dates of the Landsat scenes ranged from 2000 to 2008 (table 1). Earlier vintage Landsat imagery was used for change detection purposes, while the 2006-2008 imagery was used for actual classification. Unfortunately, significant cloud and (or) snow cover was present in much of the acquired Landsat imagery, particularly over forested lands. Additionally, a near infrared band (NIR) anomaly caused by cloud cover was detected in several of these scenes. If uncorrected, these issues would have adversely affected classification results.

All Landsat scenes were converted to at-sensor reflectance, to reduce inter-scene variability due to differences in solar elevation and acquisition date (Huang and others, 2002). A spatial model obtained from Utah State University (2009) was adapted to eliminate null value image artifacts, and to preserve dark value pixels (deep water, and so forth). This refined model was used to develop a graphical user interface (GUI) to perform automated reflectance transformation. Reflectance scenes were then rescaled from native floating point to unsigned 8-bit integer. Rescaled reflectance data are typically much smaller in file size than native floating point imagery. This was important because of the large geographic area of analysis. Pilot testing indicated that the use of rescaled data brought no significant loss in classification accuracy.

Landsat image data from 2008 were chosen as the "base" for this project. Areas affected by clouds in the base imagery were identified as data "gaps." Landsat scenes which were not cloud affected in these areas were then selected and subset in order to "fill" these data gaps. Whenever possible, scenes collected in 2008 were used as "fills." In cases where no such data existed, however, imagery from 2006-2007 were employed. When needed, Landsat "fill" data were normalized to the base imagery via linear regression based upon pseudo-invariant features (PIFS), which are spectrally consistent, and should not appreciably change by scene date (Eckhardt and others, 1990; Schott and others, 1988; Hadjimitsis and others, 2009). The normalized, reflectance converted, cloud-filled Landsat scenes were then mosaicked using image processing software (Cole and others, 2010).

Figure 1 (facing page). Colorado and its coniferous forests. Forested areas indicated in green, dashed lines indicate county boundaries. Base from U.S. Census Bureau TIGER/Line digital data (U.S. Census Bureau, 2009). 


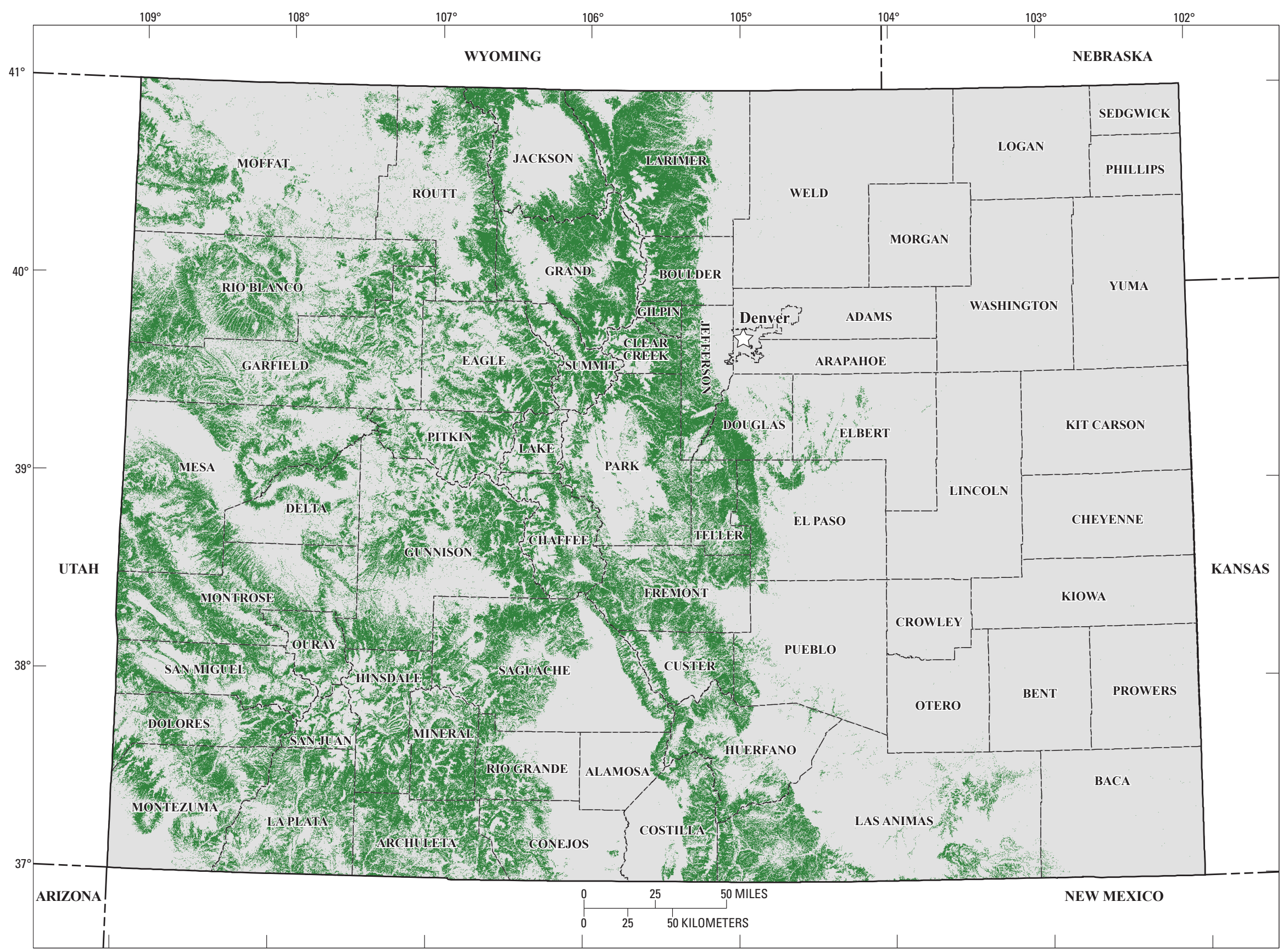




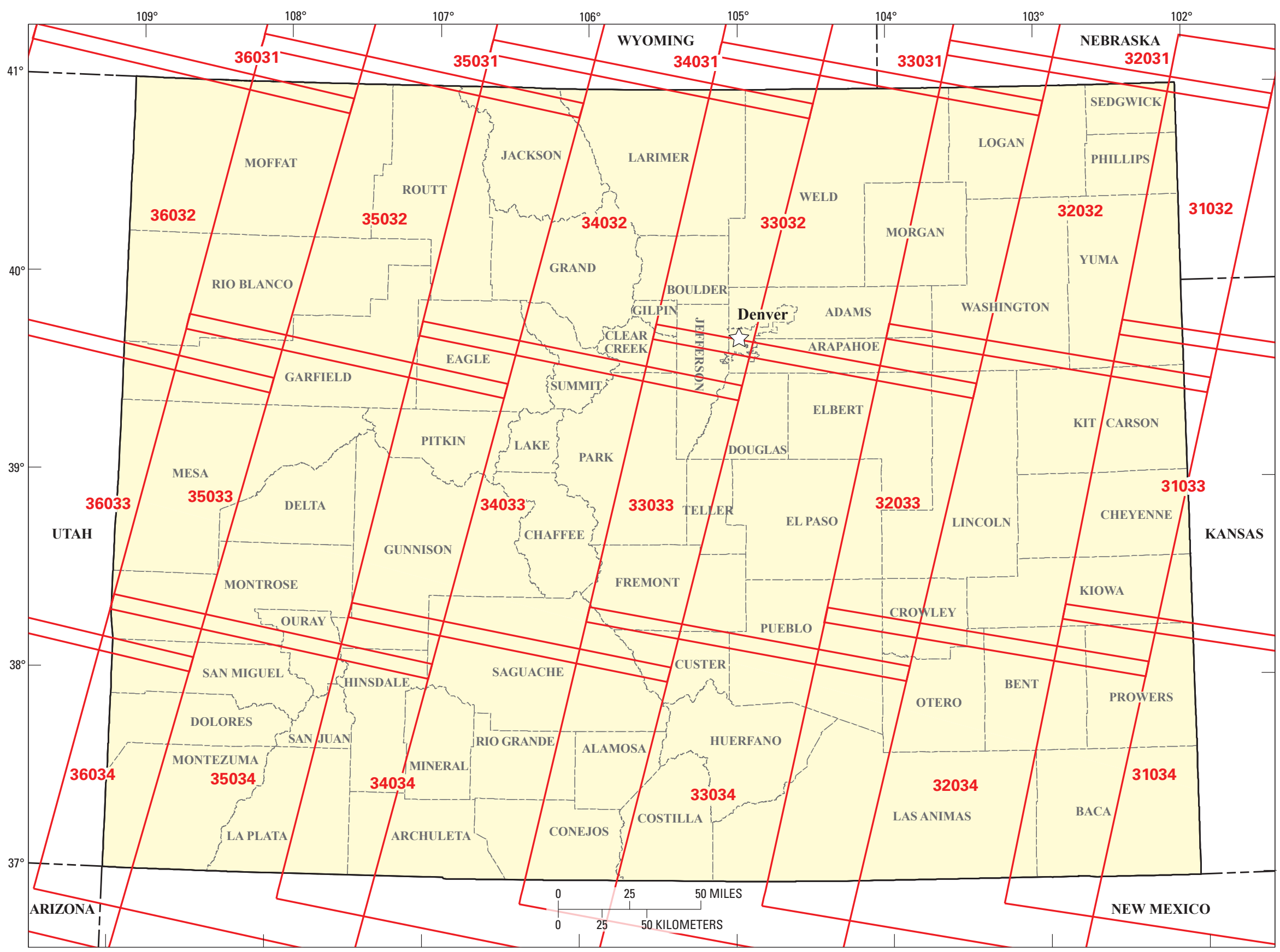


Grey-level co-occurrence matrix (GLCM) and edgedetection texture information, a Normalized Difference Vegetation Index (NDVI), and Renormalized Difference Infrared Index (RDII) were subsequently derived from the mosaicked scenes. The NDVI is defined by the equation:

$$
N D V I=\frac{N I R-R}{N I R+R}
$$

where

NIR $\quad$ is the Landsat Near Infrared Band 4,
and $\quad R \quad$ is the Red band 3.

The RDII is defined as:

$$
R D I I=\frac{N I R-S W I R}{\sqrt{N I R+S W I R}}
$$

where

$$
\text { NIR is the Landsat Near Infrared Band 4, }
$$

and

SWIR is the Shortwave Infrared band 5.

Spatial texture is useful in vegetation and impervious cover mapping. Vegetation indices have been widely employed in environmental monitoring applications. They are particularly useful in detecting/delineating healthy and (or) stressed vegetation. The RDII was derived by the USGS for the purposes of this study, and will be described in future studies.

\section{Sampling}

Two classes were identified for the purposes of this study: healthy and unhealthy conifers. Eighty-two sample points were selected for healthy conifers. Based on field observations and remote sensing theory, it was determined that if an area approximately the size of a pixel contained 20 percent or greater visibly dead trees, that pixel would be classified as "unhealthy." The number of actual dead trees varied depending on the density and type of tree species in that area. Thirty-two sample points were collected for unhealthy conifers. The samples were obtained through the collection and interpretation of field data, and Quickbird imagery. The samples were extracted from the 2008 30-m image mosaic and derivatives, to be used as training samples for supervised classification. The sampling scheme included a range of conifer species, health, and elevation range. Likely living young and mature Piñon (Pinus edulis), Ponderosa (Pinus ponderosa), and Lodgepole Pine (Pinus contorta)

Figure 2 (previous page). Colorado Landsat 5 Thematic Mapper coverage. Numbers indicate image path and row in accordance with Landsat Worldwide Reference System-2 (WRS-2). Base from U.S. Census Bureau TIGER/Line digital data (U.S. Census Bureau, 2009). Imagery obtained from USGS GloVis (U.S. Geological Survey, 2009b).
Table 1. Scenes used to derive the conifer classification, obtained from USGS Earth Resources and Observation Center

\begin{tabular}{|c|c|c|}
\hline Scene identifier & Path/row & Image date \\
\hline LT50310332008274EDC00 & $31 / 33$ & September 30, 2008 \\
\hline LT50310342008162EDC00 & $31 / 34$ & June 10, 2008 \\
\hline LT50320322008201EDC00 & $32 / 32$ & July 19, 2008 \\
\hline LT50320332007230EDC00 & $32 / 33$ & August 18, 2007 \\
\hline LT50320342008281EDC00 & $32 / 34$ & October 7, 2008 \\
\hline LT50330322008224EDC00 & $33 / 32$ & August 11, 2008 \\
\hline LT50330322008240EDC00 & $33 / 32$ & August 27, 2008 \\
\hline LT50330332008224EDC00 & $33 / 33$ & August 11, 2008 \\
\hline LT50330332008240EDC00 & $33 / 33$ & August 27, 2008 \\
\hline LT50330342007237EDC00 & $33 / 34$ & August 25, 2007 \\
\hline LT50330342008192EDC00 & $33 / 34$ & July 10, 2008 \\
\hline LT50330342008224EDC00 & $33 / 34$ & August 11, 2008 \\
\hline LT50340322006209EDC00 & $34 / 32$ & July 28, 2006 \\
\hline LT50340322006241EDC00 & $34 / 32$ & August 29, 2006 \\
\hline LT50340322007212EDC00 & $34 / 32$ & July 15, 2007 \\
\hline LT50340332006241EDC00 & $34 / 33$ & August 29, 2006 \\
\hline LT50340332007196EDC00 & $34 / 33$ & July 15, 2007 \\
\hline LT50340332007228EDC00 & $34 / 33$ & August 16, 2007 \\
\hline LT50340332008215EDC00 & $34 / 33$ & August 2, 2008 \\
\hline LT50340342006193PAC01 & $34 / 34$ & July 12, 2006 \\
\hline LT50340342006241EDC00 & $34 / 34$ & August 29, 2006 \\
\hline LT50340342007196EDC00 & $34 / 34$ & July 15, 2007 \\
\hline LT50340342008215EDC00 & $34 / 34$ & August 2, 2008 \\
\hline LT50350322007251EDC00 & $35 / 32$ & September 8, 2007 \\
\hline LT50350322008238EDC00 & $35 / 32$ & August 25, 2008 \\
\hline LT50350332007235EDC00 & $35 / 33$ & August 23, 2007 \\
\hline LT50350332008190EDC00 & $35 / 33$ & July 8, 2008 \\
\hline LT50350332008238EDC00 & $35 / 33$ & August 25, 2008 \\
\hline LT50350342007251EDC00 & $35 / 34$ & September 8, 2007 \\
\hline LT50350342008206EDC00 & $35 / 34$ & July 24, 2008 \\
\hline LT50360322008197EDC00 & $36 / 32$ & July 15,2008 \\
\hline LT50360332008213EDC00 & $36 / 33$ & July 31,2008 \\
\hline
\end{tabular}
(EROS) (U.S. Geological Survey, 2009a). See fig. 2 for location of Landsat scenes.

were identified, as were Juniper (Juniperus sp.), spruce and fir species. Multi-year U.S. Forest Service (USFS) aerial surveys (U.S. Forest Service, 2008) were helpful for the general assessment of potential sampling sites. A stratified, random cluster method was used to constrain the points to areas where high resolution imagery was available.

\section{Landcover Mask}

Because of the explicit purposes of this classificationto identify coniferous health conditions, the USGS National Landcover Database (NLCD, 2001, http://www.mrlc.gov/ nlcd_multizone_map.php) was used to constrain analysis to these types of cover. The use of NLCD as a "mask" minimized the erroneous classification of deciduous vegetation and other cover types which may be spectrally confused with coniferous forest. This required NLCD information which was temporally synchronous to the Landsat imagery used in this study, otherwise significant mapping errors could have been perpetuated. 
An updated landcover dataset was produced for Colorado. Landsat data collected in approximately 2000 and 2001 were used in conjunction with the more recent imagery (table 1). A change detection model was used to compare the pre and post imagery and to produce an output result which was used to highlight areas of spectral change. Object-oriented analysis and classification software was used to derive vector-based image segmentations from the 2008 Landsat mosaic. Through the analysis of change detection results and multispectral imagery, image objects which identified changes to the NLCD conifer cover were attributed with a class description, comments, and a unique numeric code identifier. Image objects identifying unforested lands at the time of the original NLCD, but forested (coniferous) at the time of the 2008 imagery, were given a class value of 1 . Image objects delineating forested lands (coniferous) at the time of the original NLCD, but unforested at the time of the 2008 imagery were given a value of 2. Additionally, a spatial model was developed which utilized texture information derived from Landsat multispectral band 3, and the U.S. Census Bureau TIGER/Line shapefiles (U.S. Census Bureau, 2009) to identify transportation surfaces which were erroneously classified as forested in the original NLCD. The attributed vector information and transportation layer were finally used to produce an updated landcover dataset which more accurately characterized current conifer cover. Mixed forest was also included in this dataset, so as not to under-represent likely conifer cover.

\section{Classification}

The multispectral imagery and derivatives, as well as the 30-m USGS National Elevation Dataset (NED, http://ned.usgs.gov/) were evaluated using both image processing and statistical analysis software. The objective was to determine which data best discriminated healthy versus unhealthy conifer training samples. It was determined that the RDII, and the NDVI, followed by the Landsat multispectral bands and the elevation information, proved the strongest variables for this analysis.

A supervised maximum likelihood classification was performed, using the 2008 Landsat multispectral bands 2-5 and 7, NDVI, RDII, and the 30-m USGS NED, and was constrained to pixels identified in the updated landcover dataset as coniferous or mixed coniferous/deciduous vegetation. Maximum Likelihood proved superior to other pixel-based image classification algorithms tested for this study. Decision tree rule-based classification methods were tested as well, but performed marginally lower than the Maximum Likelihood approach. Additionally, a targeted unsupervised classification was implemented to resolve likely confused/misclassified conifers (predominantly Ponderosa Pine). Classification results are shown in figure 3 .
Finally, the statewide results were merged with a separate health assessment of Grand County, Colo., produced in late 2008 (unpub. data, Christopher J. Cole, Parallel, Inc., 2008). This assessment was performed using similar sampling and classification schema and methodologies as the statewide effort. However, the earlier Grand County study combined 2008 Landsat data with 2008 Advanced Spaceborne Thermal Emission and Reflection Radiometer (ASTER) imagery. This multi-sensor data integration was necessary in order to miminize cloudcover and facilitate analysis. Classification was performed upon a three band (green, red, near infrared) multispectral image mosaic, resampled to $30-\mathrm{m}$ to match the spatial resolution of Landsat data. Without the inclusion of this classification, a significantly larger portion of the State assessment would have been derived using pre-2008 imagery. This was not desirable because ongoing USGS work within Grand County has confirmed significant vegetation mortality which would not have been captured using earlier data.

\section{Results and Verification}

An accuracy assessment was performed using seventytwo stratified, randomly selected samples which were not used as training sites for image classification (fig. 4). These samples were selected using the same data and methods employed to derive training samples for the supervised classification, with the exception of six points which were assessed by field visits.

Field verification of the classification results was also accomplished using an Xplore tablet computer configured with GPS (Global Positioning System) and Global Mapper image analysis software. Over 500 miles of conifer forest were inspected by driving along the roads (road surveys). This approach was chosen because it proved to be a relatively efficient means of field verification, and facilitated the inspection of a large amount of territory in order to assess vegetation condition. Additional verification was done by field visits to six areas of potential classification confusion. Data including GPS points with notes, and photographs were taken during these visits. The road survey verification covered the areas northeast of Fort Collins and continued down through Estes Park, Leadville, west of Colorado Springs, and ending just southwest of Alamosa. Unfortunately, due to time constraints, it was not possible to conduct field visits in the western and southwestern portions of the State.

Figure 3 (facing page). Conifer health classification for Colorado, derived from Landsat imagery (U.S. Geological Survey, 2009b). Image derivatives, and updated National Land Cover Database from U.S. Geological Survey (2009a). Base from U.S. Census Bureau TIGER/Line digital data (U.S. Census Bureau, 2009). 


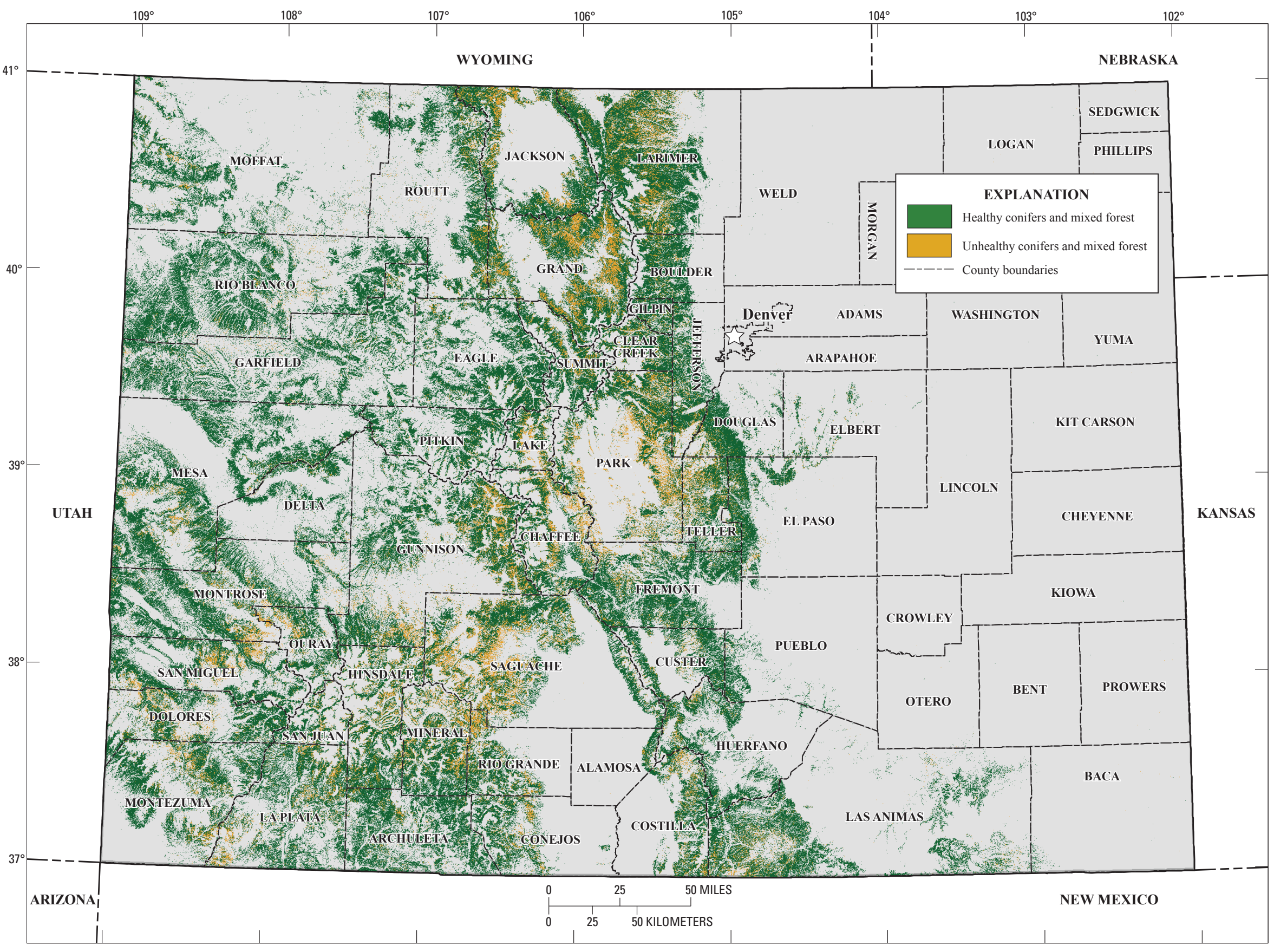




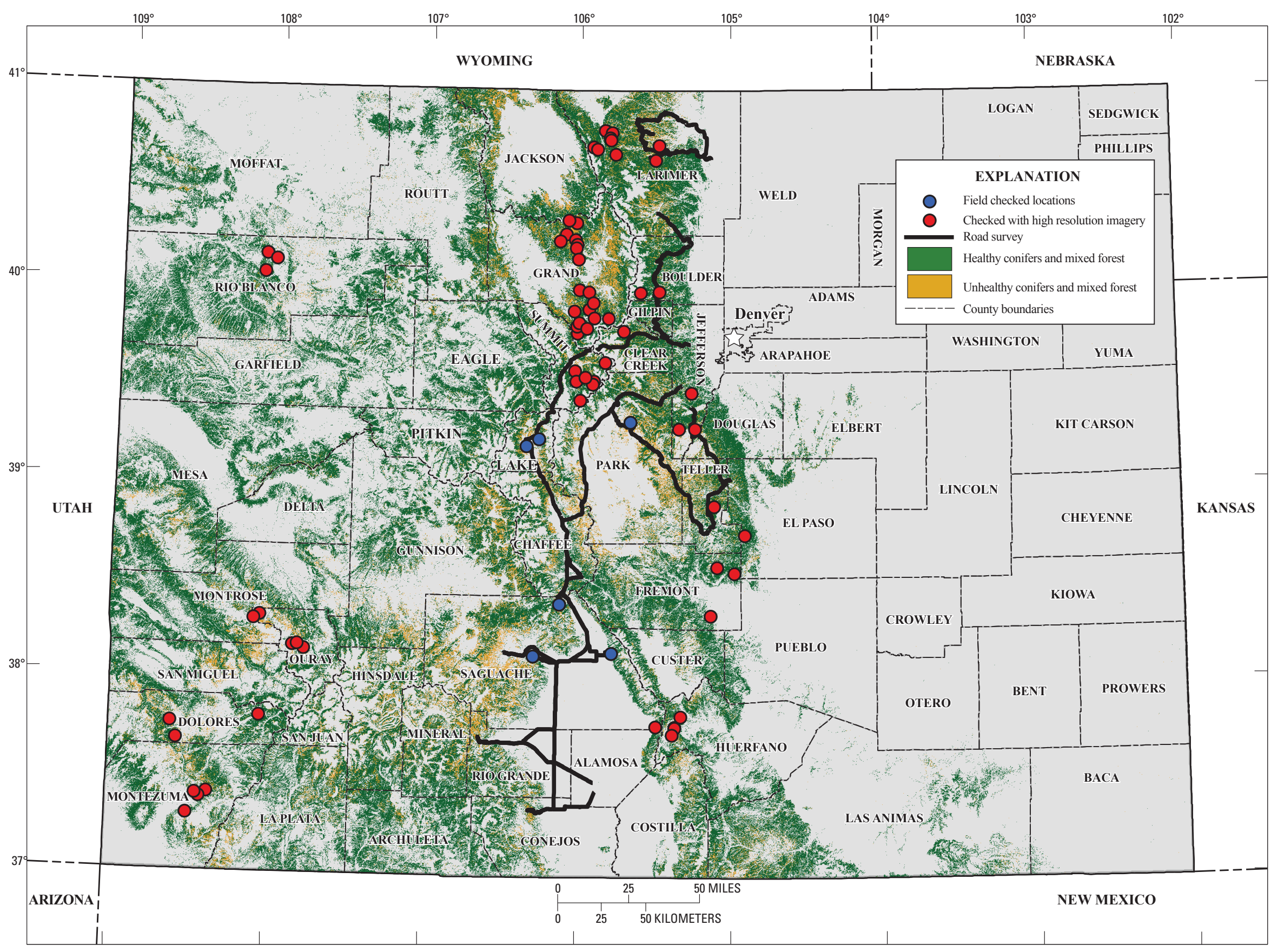


Figure 4 (previous page). Accuracy assessment locations. Locations of potential classification confusion where the conifer classification was verified by doing inspections by driving along the roads (road survey, in black), and also by field checking specific sites (blue dots). Red dots indicate a location that was checked by using Quickbird imagery. Conifer health classification for Colorado, derived from Landsat imagery (U.S. Geological Survey, 2009b). Image derivatives, and updated National Land Cover Database from U.S. Geological Survey (2009a). Base from U.S. Census Bureau TIGER/Line digital data (U.S. Census Bureau, 2009).

Classification results are summarized in table 2. The overall classification accuracy of 86 percent attained in this report strongly suggests that the data and methods used successfully characterized conifer conditions within Colorado. It should be noted, however, that this accuracy rate may be partly attributed to the limited scope of this report. As such, all other landcover classes and vegetation types were excluded from this report, a fact which no doubt reduced potential classification confusion, and enhanced mapping accuracy.

Despite the acceptable accuracy obtained in this study, uncertainty existed when discerning vegetation cover type and condition. One example of this problem pertains to Piñon-Juniper communities. Both healthy and unhealthy Piñon (Pinus edulis) and Juniper (Juniperus sp.) vegetation tend to exhibit spectral reflectance properties similar to other unhealthy conifer types. Additionally, healthy, low density Ponderosa Pine (Pinus ponderosa) prove spectrally similar to (and can be confused with) unhealthy conifers. This confusion between classifications can be partially attributed to the prevalence of "background" cover type-typically exposed rock and (or) sparsely vegetated soils.

Confusion between classifications may also be attributed in part to the relative lack of field data available. Followon classifications efforts should incorporate additional field sampling collection. It is also possible that some data confusion could be addressed through the use of change detection procedures involving pre/post Landsat imagery. This would have involved the derivation of a "pre-change" image mosaic. However, due to time constraints, this was not an option as this would have significantly increased image processing procedures.

It is likely that unhealthy conifer cover in areas such as Summit County were underrepresented in this classification. This may be explained by the lack of cloud-free post-2006 Landsat imagery spanning this area. Because of the vintage of the imagery, it did not capture the ongoing, recent conifer mortality within this County. It is worth noting that although it was not ideal to utilize mixed methodologies, the inclusion of results obtained from the Grand County assessment clearly produced a more timely, accurate depiction of conifer condition, and further minimized classification limitations due to date of image coverage.

The accuracy assessment results found in table 2 presents the classification results of healthy and unhealthy conifers relative to the actual vegetation type on the ground. Point samples were taken at 72 locations and verified either through field visits or from higher-resolution Quickbird imagery. The 'number correct' column shows how many of these points agree with the map label. Conversely, the inaccuracies of each class are described as 'user's accuracy (for example, errors of inclusion or commission) and 'producer's accuracy' (for example, errors of exclusion or omission). The user's accuracy indicates how many polygons for each map unit were incorrectly labeled, or over-mapped, when compared to the ground data. The producer's accuracy provides information on how many polygons for each conifer type were left off the map, or under-mapped. Overall classification accuracy gives a percentage of the total correct sample pixels divided by the total sample pixels (for example, 62/72). The Kappa statistic is an index that allows us to measure agreement against that which might be expected by chance. Possible values range from +1 (perfect agreement) to 0 (no agreement above that expected by chance) to -1 (complete disagreement).

Much of the classification uncertainty may be primarily due to the spatial resolution of the Landsat imagery used to complete this report. It is hypothesized that high- to moderateresolution multispectral imagery could significantly reduce the uncertainty rates. This will be investigated and used for future sampling, analysis, and validation efforts.

Table 2. Accuracy assessment results for the conifer classification.

[Column headers are as follows: Sample totals, the number of point sample locations; Classified totals; the number of samples that were classified as either unhealthy or healthy conifer; Number correct, the number of sample sites that were deemed correct when compared to field or high resolution imagery; Producer's accuracy, the number of correct samples divided by the sample total; User's accuracy, the number of correct samples divided by the classified total]

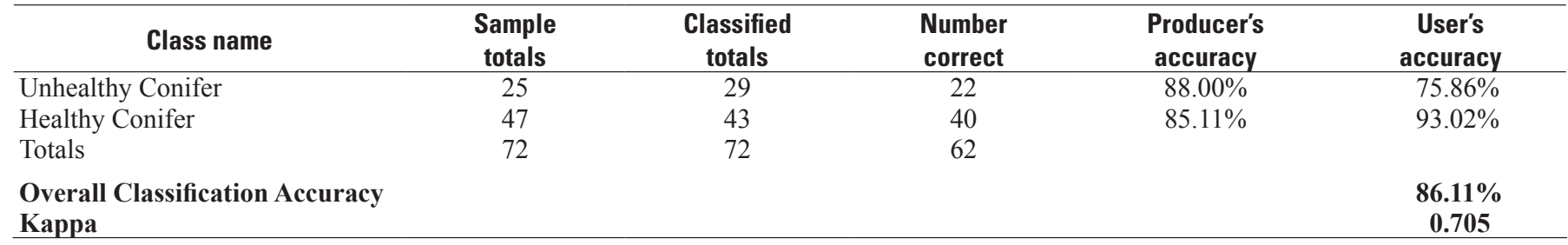




\section{Summary}

The RMGSC used medium-resolution Landsat remotely sensed imagery for the assessment of conifer health in 2008. Landsat 5 Thematic Mapper imagery were collected statewide, and converted to at-sensor reflectance to reduce inter-scene variability due to differences in solar elevation and acquisition date The use of USGS NLCD information greatly contributed to the success of this study. However, the datasets currency and concomitant classification accuracy proved problematic in many instances. We attempted to expediently produce an updated, accurate dataset which would meet the scope of the project in a short timeline. However, the NLCD contains inherent limitations due to the temporal currency of the Landsat source data from which it was derived. Because of this fact, the use of the NLCD did somewhat affect classification accuracy.

A decision tree rules-based classification approach was tested in an earlier pilot study spanning Grand County. This study had slightly lower classification results than the maximum likelihood algorithm used for that assessment. Nonetheless, the decision tree method performed well, and has been effectively used for similar medium-resolution mapping efforts across large geographic scales in other studies, and thus will likely be further examined.

Finally, it is also important to distinguish the results of our study from aerial surveys flown yearly by the USFS. Aerial surveys, while useful for determining general forest conditions, pose considerable challenges related to analytical interpretability and concomitant usage with remotely sensed imagery for Earth observation. If used incorrectly, surveys may lead to false conclusions drawn regarding forest mortality (for example, in spatial scale and density). Additionally, it should be understood that the USGS and USFS products were designed for somewhat dissimilar purposes, and have different intended applications. As such, the products should be described as complementary, and care should be taken not to directly compare them.

Despite these uncertainties, we feel a repeatable, landscape-level assessment of coniferous forest health statewide was produced from this data. It is believed that high- to moderate-resolution multispectral imagery, coupled with field data, could significantly reduce the uncertainty rates. This will be investigated and used for subsequent sampling, analysis, and validation efforts.

\section{Acknowledgments}

The authors wish to thank Catherine Costello and Richard V. Poss, U.S. Geological Survey, who aided in the NLCD update process. We would also like to recognize Harumi Warner of Parallel, Inc., who provided input and technical support pertaining to cartography and image editing.

\section{References Cited}

Cole, C.J., Noble, S.M., Blauer, S.L., Friesen, B.A., and Bauer, M.A., 2010, Landsat Thematic Mapper image mosaic of Colorado: U.S. Geological Survey Scientific Investigations Map 3101, scale 1:650,000, 1 sheet.

Eckhardt, D.W., Verdin, J.P., and Lyford, G.R., 1990, Automated update of an irrigated lands GIS using SPOT HRV imagery: Photogrammetric Engineering and Remote Sensing, v. 56, p. 1515-1522.

Elvidge, C.D., and Chen, Zhikang, 1995, Comparison of broad-band and narrow-band red and near-infraredvegetation indices: Remote Sensing of Environment, v. 54 , p. $38-48$.

Hadjimitsis, D.G., Clayton, C.R.I., and Retalis, Adrianos, 2009, The use of selected pseudo-invariant targets for the application of atmospheric correction in multi-temporal studies using satellite remotely sensed imagery: International Journal of Applied Earth Observation and Geoinformation, v. 11, no. 3, p. 192-200.

Huang, Chengquan, Wylie, Bruce, Yang, Limin, Homer, Collin, and Zylstra, Gregory, 2002, Derivation of a tasselled cap transformation based on Landsat 7 at-satellite reflectance: International Journal of Remote Sensing, v. 23, no. 8, p. 1741-1748.

Nonaka, Etsuko, and Spies, T.A., 2005, Historical Range of Variability in Landscape Structure-A Simulation Study in Oregon, USA: Ecological Applications, v. 15, p. 1727-1746.

Schott, J.R., Salvaggio, Carl, and Wolchock, W.J., 1988, Radiometric scene normalisation using pseudo-invariant features: Remote Sensing of Environment, v. 26, p.1-16. 
U.S. Census Bureau, 2009, TIGER/Line Shapefiles: U.S. Census

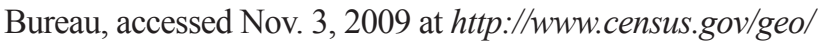
www/tiger/tgrshp2009/tgrshp2009.html.

U.S. Forest Service, 2008, Rocky Mountain Region forest insect and disease aerial survey, accessed January 22, 2010 at $h t t p: / / w w w . f s . f e d . u s / r 2 /$ resources/fhm/aerialsurvey/.

U.S. Geological Survey, 2006, National Elevation Dataset (NED): U.S. Geological Survey, accessed June 30, 2009 at http://ned.usgs.gov/.

U.S. Geological Survey, 2009a, Multi-Resolution Land Characteristics Consortium, National Landcover Database (NLCD) 2001: U.S. Geological Survey, accessed June 30, 2009 at http://www.mrlc.gov/nlcd_multizone_map.php.

U.S. Geological Survey, 2009b, USGS Global Visualization Viewer (GloVis): U.S. Geolgical Survey, accessed June 30, 2009 at http://glovis.usgs.gov/BrowseBrowser.shtml.

Utah State University, 2009, Remote Sensing/Geographic Information Systems Laboratory, DN-to-Reflectance Image Standardization Tool: Logan, Utah State University, College of Natural Resources, accessed June 30, 2009 at http://earth.gis.usu.edu/imagestd/.
Veblen, T.T., and Donnegan, J.A., 2005, Historical range of variability assessment for forest vegetation of the National Forests of the Colorado Front Range: U.S. Department of Agriculture Forest Service, Rocky Mountain Region. Agreement no. 1102-0001-99-033 with the University of Colorado, Boulder, 153 p., accessed June 30, 2009 at $h t t p: / / w w w . f s . f e d . u s / r 2 /$ projects/scp/tea/ HRVFrontRange.pdf.

Vogelmann, J.E., 2002, Monitoring northeastern United States forest condition using Landsat data in Integrated remote sensing at the global, regional and local scale, ISPRS Commission I mid-term symposium in conjunction with Pecora 15/ land satellite information IV conference 10-15 Nov. 2002, Denver, Colo., Proceedings: Denver, Colo., International Society for Photogrammetry and Remote Sensing (ISPRS), available at $h t t p: / / w w w . i s p r s . o r g / c o m m i s s i o n 1 /$.

Vogelmann, J.E., and Rock, B.N., 1988, Assessing forest damage in high-elevation coniferous forests in Vermont and New Hampshire using Thematic Mapper data: Remote Sensing of Environment, v. 24, p. 227-246.

Publishing support provided by:

Denver Publishing Service Center, Denver, Colorado

Manuscript approved for publication, June 23, 2010

For more information concerning this publication, contact: Center Director, USGS Rocky Mountain Geographic Science Center Box 25046, Mail Stop 516

Denver, C0 80225

(303) 202-4106

Or visit the Rocky Mountain Geographic Science Center Web site at: http://rmgsc.cr.usgs.gov/rmgsc/

This publication is available online at: http://pubs.usgs.gov/sim/3103/ 


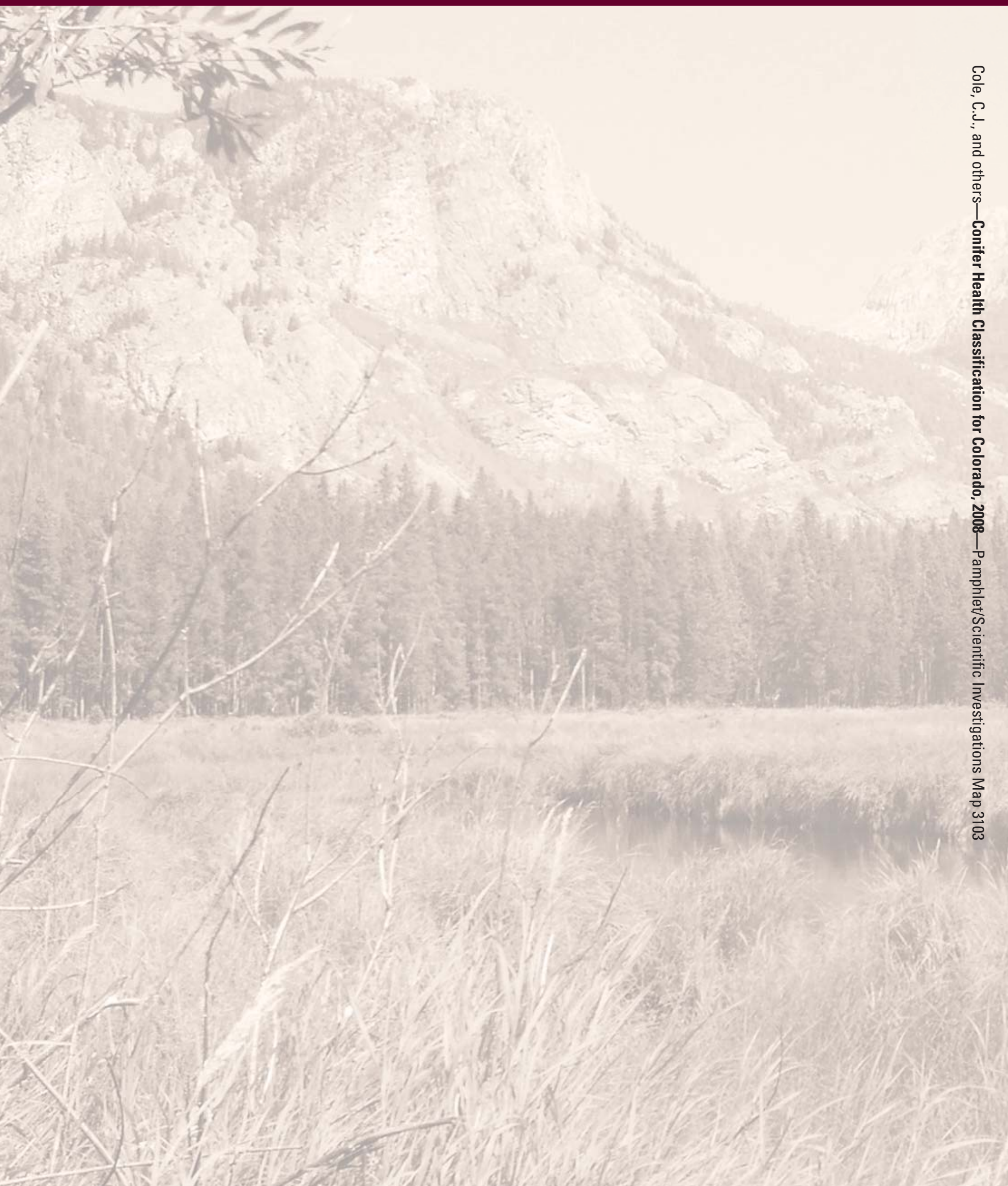

